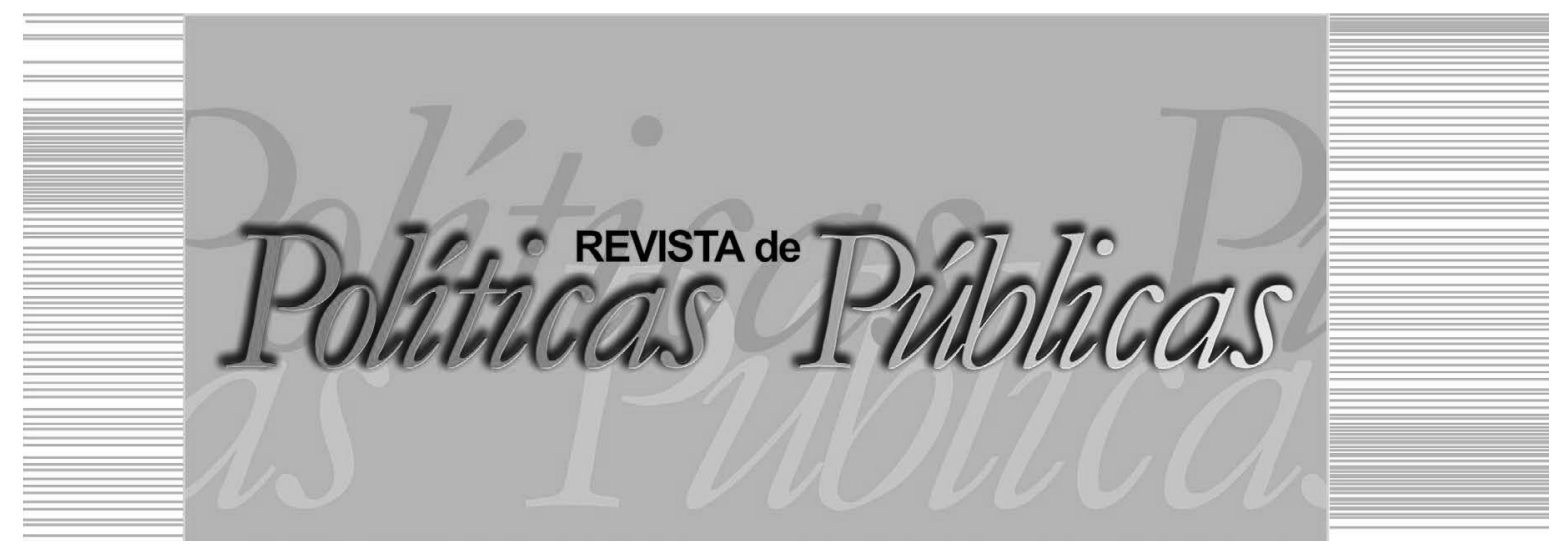

\title{
EXTRATIVISMO DE MARISCOS NA ILHA DO MARANHÃO (MA): implicações ecológicas e socioeconômicas
}

\author{
Tatiana de Jesus Ferreira Pereira ${ }^{I}$ \\ Antonio Carlos Leal de Castro ${ }^{2}$ \\ Helen Roberta Silva Ferreira ${ }^{3}$ \\ Leonardo Silva Soares ${ }^{4}$ \\ Marcelo Henrique Lopes Silva ${ }^{5}$ \\ James Werllen de Jesus Azevedo ${ }^{6}$ \\ Victor Lamarão de França ${ }^{7}$ \\ Michelly dos Santos Moreira ${ }^{8}$
}

\footnotetext{
Graduada em Engenharia de Pesca, Mestre em Sustentabilidade de Ecossistemas, Pesquisadora da Universidade Federal do Maranhão (UFMA). E-mail: tati.engpesca@gmail.com

2 Engenheiro Agrônomo, Doutor em Ciências da Engenharia Ambiental, Professor Departamento de Oceanografia e Limnologia (DEOLI) da UFMA. E-mail: alec@ufma.br

${ }^{3}$ Oceanógrafa, Mestranda em Oceanografia, Pesquisadora da UFMA. E-mail: nelehroberta@ hotmail.com

${ }^{4}$ Graduado em Ciências Aquáticas, Doutor em Desenvolvimento e Meio Ambiente, Professor da UFMA. E-mail: leonardoufma@yahoo.com.br

5 Oceanógrafo, Doutorando do Programa Biodiversidade e Biotecnologia pela Rede BIONORTE na UFMA. E-mail: marceloh10@gmail.com

${ }^{6}$ Graduado em Ciências Aquáticas, Mestre em Sustentabilidade de Ecossistemas, Pesquisador da UFMA. E-mail: jameswerllen@yahoo.com.br

7 Graduado em Ciências Aquáticas, Mestre em Saúde e Ambiente, Pesquisador da UFMA. E-mail: lamaraovf@yahoo.com.br

8 Oceanógrafa, Pesquisadora da UFMA. E-mail: michelly.m@outlook.com / Universidade Federal do Maranhão - UFMA: Av. dos Portugueses, 1966, Bacanga, São Luís - MA. CEP 65080-805.
} 
Tatiana de Jesus Ferreira Pereira $\mid$ Antonio Carlos Leal de Castro $\mid$ Helen Roberta Silva Ferreira $\mid$ Leonardo Silva Soares, Marcelo Henrique Lopes Silva | James Werllen de Jesus Azevedo | Victor Lamarão de França

\title{
Resumo
}

Esta pesquisa avaliou o sistema de produção extrativista de moluscos e os efeitos socioeconômicos e ambientais nos municípios de Paço do Lumiar, São José de Ribamar e Raposa, situados na Ilha do Maranhão. Foram realizadas entrevistas no período entre setembro/2014 e dezembro/2014, com aplicação de 66 questionários do tipo semiestruturados, abordando a questão ambiental, socioeconômica e a atividade de mariscagem e coletadas alíquotas de água para análise bacteriológica nos sítios de extração dos mariscos. A evolução espaço-temporal dos bancos que servem de substrato para os moluscos foi avaliada a partir de imagens aéreas referente aos anos de 2005 e 2015. Os principais moluscos extraídos foram Anomalocardia brasiliana, Mytellafalcata, Mytellaguanienses, Iphigenia brasiliensis e Crassostrearhizophorae, os quais apresentaram produção estimada entre $200 \mathrm{Kg}$ a $300 \mathrm{Kg}$ /coleta.

Palavras-chave: Moluscos, catadores, estuário, Ilha do Maranhão.

\section{EXTRACTIVISM OF SHELLFISH IN THE ISLAND OF}

MARANHÃO (MA): ecological and socioeconomic implications

\begin{abstract}
This study evaluated the extractive production system of molluscs and the socioeconomic and environmental effects in the municipalities of Paço do Lumiar, São José de Ribamar and Raposa, located in Maranhão Island. Interviews were conducted between September/14 and December/14. A total of 66 standardized questionnaires were applied, approaching environmental issues, socioeconomic and extractive activity. Aliquots of water were collected to bacteriological analysis in shellfish extraction sites. The spacetime evolution of the base that serve as the substrate for molluscs was assessed from aerial images of reffered to the years 2005 and 2015. The main mollusks extracted were Anomalocardiabrasiliana, Mytellafalcata, Mytellaguanienses, Iphigenia brasiliensis and Crassostrearhizophorae, which had an estimated production of $200 \mathrm{~kg}$ to $300 \mathrm{~kg} /$ collection.
\end{abstract}

Key words: Molluscs, gatherers, estuary, Maranhão Island.

\section{INTRODUÇÃO}

O extrativismo de moluscos bivalves é uma importante atividade econômica em várias comunidades costeiras no Nordeste brasileiro, sendo que cerca de 50.000 pessoas vivem exclusivamente da coleta de moluscos como a ostra (Crassostreagasar), o sarnambi (Anomalocardia brasiliana) e o sururu (Mytellafalcata e Mytellaguyanensis) em estuários e manguezais. (CASTRO et al., 2014). 
Os efeitos da pesca predatória e a degradação ambiental em áreas costeiras produzem uma diminuição na renda dos pescadores artesanais e ameaçam fortemente a atividade produtiva dependente do extrativismo. A falta de emprego nas comunidades litorâneas atrai um número cada vez maior de pessoas sem qualificação profissional para atividades extrativas, aumentando a pressão sobre os recursos naturais. (POLI, 1996).

No litoral maranhense, a extração de moluscos tem papel fundamental na complementação da renda de famílias de pescadores. Desenvolvida de forma rústica, a prática extrativista envolve a catação de sarnambi, sururu, ostra, unha de velho e demais pescados de importância comercial ou apenas alimentícia para essas famílias.

A caracterização da forma de produção e estratégia de conservação dos recursos pesqueiros são fundamentais para a compreensão do hábito de vida das comunidades de pescadores e sua inter-relação com o ambiente explorado.

Schaeffer-Novelli (1989) assinala que as capturas de ostra (Crassostreasp), sururu (Mytellafalcata) e sarnambi (Anomalocardia brasiliana) estão entre as de maior destaque em áreas estuarinas e de manguezais do nordeste brasileiro, recebendo a denominação de mariscagem.

A atividade extrativa é baseada na unidade familiar ou no grupo de vizinhança, sendo importante na geração de renda e como fonte de alimento de alto valor nutricional para comunidades de pescadores artesanais ribeirinhos. Estas comunidades executam a catação a partir dos conhecimentos culturais e costumes consolidados por gerações sobre os ciclos naturais das espécies exploradas, procurando manter o seu modo de vida e assegurar o manejo sustentável dos recursos naturais visando à conservação. (DIEGUES, 1983; SCHAEFFER-NOVELLI,1999).

A grande participação de mulheres na prática da mariscagem (marisqueiras) assegura a igualdade de gêneros na organização produtiva da atividade, permitindo um incremento na renda das populações que dependem fortemente da extração de recursos pesqueiros estuarinos.

Identificaram-se poucos estudos sobre o desenvolvimento da atividade de mariscagem na Ilha de São Luís, com destaques para Moreira (2007), que estudou a ecologia do sarnambi capturado no 
estuário do Rio Cururuca, município de Paço do Lumiar, Funo e outros (2012) e Monteles e outros (2009) que avaliaram, respectivamente, os saberes tradicionais e a percepção ambiental das marisqueiras do município de Raposa.

No entanto, a coleta desses recursos por centenas de pessoas, aliada a décadas de exploração sem planejamento e controle, tem levado à exaustão dos estoques naturais com sérias consequências ambientais e socioeconômicas.

Nesse contexto, o presente estudo visa contribuir com a proposição de formas de manejo sustentável para o desenvolvimento da atividade extrativista de moluscos na Ilha do Maranhão e detectar como estão estruturadas as relações socioeconômicas e ambientais da comunidade com a prática da mariscagem.

\section{MATERIAL E MÉTODOS}

A Ilha do Maranhão é constituída pelos municípios de São Luís, São José de Ribamar, Paço do Lumiar e Raposa

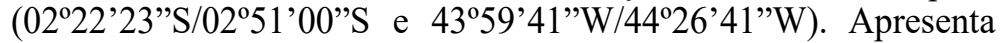
uma área superficial de $831,7 \mathrm{Km}^{2}$; limita-se ao norte com o Oceano Atlântico; ao sul, com a baía de Arraial e o estreito dos Mosquitos; a leste com a baía de São José e a oeste com a baía de São Marcos (Figura 1). Inserida no Golfão Maranhense, contém feições morfológicas que compreendem planícies de maré lamosas e arenosas, praias dissipativas de areias finas quartzosas, dunas móveis e fixas, falésias, pontais rochosos, restingas e manguezais. (FEITOSA; TROVÃO, 2006).

Figura 1 - Mapa de Localização da Ilha do Maranhão

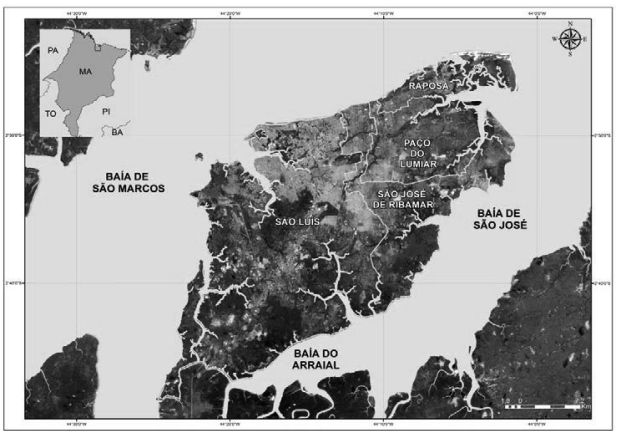

Fonte: Elaborada pelos autores.

Os dados que dão suporte a este trabalho foram obtidos através de entrevistas realizadas no período de setembro/2014 a dezem- 
bro/2014 nas comunidades de Timbuba (Paço do Lumiar), São Raimundo (São Jose de Ribamar) e Porto do Braga (Raposa), sempre precedidas pela identificação do entrevistador e por uma rápida explanação sobre o trabalho.

Os participantes foram esclarecidos sobre os objetivos e métodos propostos para obtenção dos dados, sendo assegurado a eles o direito de acesso aos mesmos. O Termo de Consentimento Livre e Esclarecido (TCLE) foi apresentado com o propósito de poder utilizar as informações, garantindo o sigilo da identidade dos participantes e a liberdade de recusar a participar da pesquisa.

Inicialmente foram realizadas entrevistas livres com informantes, objetivando-se conhecer aspectos mais gerais da comunidade nativa do ecossistema manguezal local e das práticas de exploração nele desenvolvidas, buscando elencar as principais ações identificadas pelas comunidades, representantes, lideranças e catadores mais experientes na região.

A amostra dos informantes foi definida a partir de indivíduos oportunisticamente encontrados e pelo critério de especialistas nativos, que são aquelas pessoas reconhecidas pela própria comunidade como experientes e culturalmente competentes. (MARQUES, 1995).

Dada a quantidade de pessoas na comunidade que só recentemente passaram a exercer práticas de mariscagem, optou-se ainda por incluir no universo amostral aqueles profissionais com pelo menos 10 anos de experiência na área, considerando ser este um tempo razoável para a aquisição de um conhecimento apurado da dinâmica e dos componentes do ecossistema manguezal local. (CORDELL, 2001).

A ampliação amostral foi possibilitada pela inclusão de novos indivíduos, sucessivamente indicados pelos anteriormente contatados. Gradualmente, constituiu-se uma rede conexiva que evidenciou altos níveis de consistência informativa, o que foi considerado suficiente para caracterizar um bom tamanho para a amostra. (ALEXIADES, 1996).

Os questionários aplicados foram do tipo semiestruturado que abordaram a questão ambiental e o perfil socioecnômico da população de catadores de moluscos, incluindo as seguintes variáveis: 
faixa etária, escolaridade, estado civil, tipo de moradia, número de habitantes, renda mensal, saneamento, saúde e educação.

Dentre os itens referentes à prática da mariscagem, observaram-se: tempo de desenvolvimento da atividade, utensílios utilizados, tecnologias e manejo aplicados (durante e pós mariscagem), espécies e volumes capturados, formas de comercialização dos mariscos e importância ambiental do ecossistema manguezal.

Nas visitas aos sítios de extração dos mariscos foram tomadas alíquotas de água para análises microbiológicas através da técnica dos tubos múltiplos, com o propósito de determinar o Número Mais Provável de Coliformes totais, termotolerantes e identificação de Escherichia coli. As amostras de água foram recolhidas aproximadamente a 50 centímetros de profundidade da superfície, utilizando-se frascos esterilizados com capacidade para $250 \mathrm{~mL}$. Em seguida, as amostras foram transportadas em caixas isotérmicas para o Laboratório de Microbiologia da Universidade Federal do Maranhão, onde se utilizou a técnica dos tubos múltiplos seguindo a metodologia preconizada pela American Public Health Association (APHA, 2005).

No laboratório, amostras de mariscos adquiridas nos locais de extração tiveram seu tecido muscular removido e pesado de maneira a formar cinco replicatas de aproximadamente 4 gramas, cada, para análise microbiológica. As amostras foram desidratadas $\left(24 \mathrm{~h}, 105^{\circ}\right)$ e digeridas com solução de ácido nítrico + água $\left(\mathrm{HNO}_{3}+\mathrm{H}_{2} \mathrm{O}\right)(1: 1)$ e $150 \mu \mathrm{L}$ de octanol $\left(\mathrm{C}_{8} \mathrm{H}_{18} \mathrm{O}\right)$, seguindo as recomendações de Carvalho e outros (2000).

A evolução espaço-temporal dos bancos dos mariscos foi avaliada a partir de imagens aéreas de alta resolução para os anos de 2005 e 2015. Delimitou-se um raio de $3 \mathrm{Km}$ equidistante da área central do banco, como um buffer para identificar possíveis alterações nas unidades de paisagem do entorno com potencial de redução da abundância e densidade dos mariscos explorados.

Para análise de processamento de imagens foram utilizados os seguintes arquivos: Imagens Landsat-5, TM, multiespectral, bandas 3, 4 e 5, com passagem em 16/07/2005, órbita/ponto: 220/62 e Imagens Landsat-8, OLI, multiespectral, bandas 2, 3,4, 6 e 7, referente à data de 12/07/2015, órbita/ponto: 220/62, juntamente com 0 programa para processamento de imagem, SPRING 5.1.3. 
Utilizaram-se sensores TM e OLI dos satélites Landsat 5 e Landsat 8, respectivamente, com uma resolução espacial de $30 \mathrm{~m}$, permitindo a visualização de diferentes classes da cobertura, uso e ocupação do solo.

\section{RESULTADOS E DISCUSSÃO}

Souto (2004) considera que a extração de moluscos pode ser entendida através da observação, compreensão e decodificação desta atividade exploratória em cada uma das conexões básicas que os membros da comunidade mantêm com o ecossistema manguezal.

Assentado nessa base conceitual caracterizou-se o perfil socioeconômico das comunidades pesquisadas, sendo identificados os principais tensores ambientais assinalados pelas comunidades investigadas. Foram aplicados 66 questionários nos três municípios da Ilha do Maranhão, distribuídos da seguinte maneira: Paço do Lumiar (40), São José de Ribamar (14) e Raposa (12).

As informações coletadas nas entrevistas com as lideranças indicaram uma redução na atividade de mariscagem, sendo os principais problemas citados a falta de saneamento básico, o lançamento de esgotos domésticos, desmatamento dos mangues e o despejo de lixo, os quais foram destacados como responsáveis pela redução do estoque de moluscos em várias localidades.

Os resultados indicam que a atividade de mariscagem desenvolvida na Ilha do Maranhão é praticada por trabalhadores que possuem, em sua maioria, nível de escolaridade de ensino fundamental incompleto, que corresponde entre $44,44 \%$ a $50,00 \%$, seguido por analfabetismo com $11,11 \%$ a $28,57 \%$. Os registros apontam que o município de São José de Ribamar apresentou os maiores percentuais de indivíduos analfabetos e com o ensino fundamental incompleto. Baixo nível também foi encontrado por Rocha (2010) no estuário do rio Mamanguape, Paraíba, que registrou $33 \%$ de mulheres com o ensino fundamental incompleto e $27 \%$ de analfabetas, enquanto Castilho-Westphal e outros (2014) identificaram $62 \%$ de extratores com ensino fundamental incompleto na comunidade extrativista da baía de Guaratuba, Paraná.

Os dados obtidos nesta pesquisa corroboram as informações mencionadas por Daltro (2013) ao descrever índices socioeconômicos dos pescadores e marisqueiras de São Francisco do Conde (BA), 
na qual verificou que $67,7 \%$ dos pescadores e marisqueiras possuíam o ensino fundamental incompleto e $6,5 \%$ eram analfabetos.

Conforme Daltro (2013) e Nishida, Nordi e Alves (2008), o alto índice de baixa escolaridade dos trabalhadores na pesca artesanal (pescadores e marisqueiras) pode estar relacionado com os fatores como: aspecto cultural da unidade familiar (geralmente os pais levam seus filhos para a pescaria de forma a aprender esta arte), dificuldade de acesso e condições de permanência dos trabalhadores na escola; o desinteresse dos indivíduos pela educação, etc. Essas condições representam uns dos fatores determinantes na classificação da pesca artesanal como primitiva, dificultando sua contextualização e a possibilidade de elaboração de políticas públicas.

Foram registrados, também, os tipos de moradias das comunidades pesquisadas, onde ficaram evidentes as características peculiares das habitações, com predomínio de moradia de alvenaria, que representou mais de $75 \%$ do total assinalado.

Os domicílios dos entrevistados possuíam entre 1 a 9 habitantes, cuja média foi de 4,19 $\pm 2,18$ indivíduos/residência, sendo que os municípios de São José de Ribamar, Raposa e Paço do Lumiar expressaram 3,71 $\pm 2,73,4,75 \pm 1,36$ e 4,19 $\pm 2,18$ indivíduos/casa, respectivamente. Observou-se que $45,46 \%$ a $83,34 \%$ das residências tinham 4 a 6 pessoas/domicílio, e as residências com 1 a 3 e com mais de 7 pessoas totalizaram 8,33\% (Raposa), 17,39\% (Paço do Lumiar) e 27,27\% (São José de Ribamar).

Em relação ao quantitativo de pescadores/marisqueiras, por domicílio, percebeu-se que as residências com 1 a 7 pessoas que praticavam a mariscagem revelaram média de 2,90土1,93 marisqueiras/domicilio. No que se refere aos municípios, São José de Ribamar

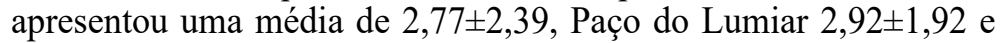

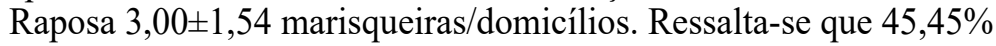
a $66,67 \%$ das residências tinham 1 a 3 marisqueiras/domicílio, e as residências com 4 a 6 pessoas e 7 ou mais pessoas totalizaram 33,33\% (Raposa), 43,48\% (Paço do Lumiar) e 54,55 \% (São José de Ribamar).

Em relação à fonte de renda das comunidades de marisqueiras pesquisadas, constatou-se que a atividade de mariscagem representa a principal fonte de obtenção de recursos financeiros, com uma variação percentual de $42,86 \%$ (Raposa) a $66,67 \%$ (São José de Ri- 
bamar). Além da mariscagem, os entrevistados relataram que a sua renda foi complementada com outras atividades como aposentadoria, ostreicultura e comércio.

A predominância da atividade mariscagem nas comunidades da Ilha do Maranhão, como fonte de renda principal, apresentou condições divergentes daquelas assinaladas por Daltro (2013) para os pescadores e marisqueiras de São Francisco do Conde (BA), que tiveram as principais fontes de rendas vinculadas a outras atividades não relacionadas com a pesca e/ou mariscagem. Quanto à atividade ocupacional, constatou-se que todas as mulheres dividem seu tempo entre as atividades de pesca e as obrigações domésticas.

No que tange à renda mensal das marisqueiras entrevistadas, foram observados valores que variaram de $\mathrm{R} \$ 160,00$ e $\mathrm{R} \$ 1.500,00$, com média de $\mathrm{R} \$ 362,69$. O município de Raposa apresentou a menor renda média mensal, que correspondeu em torno de $\mathrm{R} \$ 299,17$, seguido do município de Paço do Lumiar, que expressou uma renda média de R\$362,62 e finalizando com o de São José de Ribamar, que proporcionou a maior renda média com $\mathrm{R} \$ 417,14$. Essa renda mensal em $66,67 \%$ a $85,62 \%$ esteve complementada por auxilio de governo (Bolsa Família e Aposentaria). Rocha (2010) também assinalou o benefício do Bolsa Família como principal fonte de renda, representando $60 \%$ dos pesquisados no estuário de Mamanguape, na Paraíba, enquanto Dias, Rosa e Damasceno (2007) registraram que $56,25 \%$ das marisqueiras estudadas no Rio Grande do Norte, também possuem outra alternativa de renda.

Os resultados obtidos apresentaram semelhanças com as informações mencionadas por Moreira (2007) ao descrever os aspectos socioeconômicos do extrativismo de Anomalocardia brasiliana nos estuários dos rios Paciência e Cururuca. No estudo foi observado que a maioria das famílias de Raposa (90\%) e de Paço do Lumiar $(66,6 \%)$ apresenta renda mensal abaixo de um salário mínimo com a atividade de extrativismo de moluscos.

Os trabalhadores da atividade de mariscagem da Ilha do Maranhão possuem uma renda média mensal inferior a 1 salário mínimo vigente. Essa situação desencadeia a busca de alternativas de complementação da renda destes trabalhadores como recebimento de auxilio de governo federal (Bolsa Família, Aposentadoria e Seguro Defeso). Segundo Daltro (2013), a necessidade de complementação de renda pelos trabalhadores da pesca/mariscagem tem acres- 
cido devido ao avanço da poluição, pesca predatória e períodos de interrupção da pesca, tornando difícil sua subsistência apenas com o pescado capturado.

Quando questionados sobre o tempo que exercem a atividade, constatou-se que as marisqueiras possuem um tempo médio de $16,45 \pm 14,12$ anos, variando de 1 a 50 anos. Em análise sobre o tempo de atividade por município, observou-se que as marisqueiras do mu-

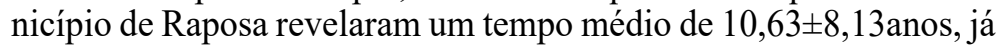
as marisqueiras de Paço do Lumiar e São José de Ribamar apresen-

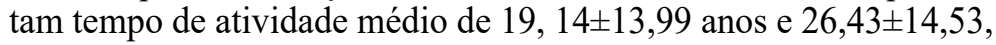
respectivamente. Ressalta-se que $21,43 \%$ a $50,00 \%$ das marisqueiras tinham até 10 anos de atividade, enquanto $14,28 \%$ a $41,67 \%$ das marisqueiras exerciam a atividade de 11 a 20 anos.

A faixa predominante do tempo de atividade das marisqueiras da Ilha do Maranhão apresenta aspectos similares aos descritos por Dias, Rocha e Damasceno (2007) para as marisqueiras da Reserva de Desenvolvimento Sustentável Ponta do Tubarão, Rio Grande do Norte, que expressaram um tempo de pesca médio de 11,5 18,8 anos, variando de 1 a 30 anos de atividades no manguezal.

Quando questionados sobre quem lhes ensinou o ofício, cerca de $80 \%$ dos entrevistados responderam que foi um legado familiar (pai, mãe, sogra, irmãos, etc.), observando-se que a atividade é exercida por pessoas com forte grau de parentesco. A coleta sempre é realizada em média 3 vezes por semana, dependendo da dinâmica da maré, e ocorre, na maioria das vezes, em grupo de 3 pessoas. Para os entrevistados, um dos grandes gargalos é a falta de embarcações, obrigando o catador a fazer uso desta por meio de troca com marisco coletado, empréstimos e aluguel.

A utilização dos recursos dos manguezais pelo homem, através dos tempos, marca uma forte ligação e associação com os fenômenos da natureza, evidências que proporcionaram o surgimento de uma cultura peculiar, representada por tradições, crenças, usos e costumes. Esta relação com o ambiente é passada verbalmente entre as gerações, num verdadeiro correr de boca em boca, na qual é observada uma forte influência indígena. (VERGARA-FILHO; VILLAS BOAS, 1996).

A exploração dos recursos do mar se caracteriza como fonte de renda e sustento de todas as famílias, considerando a qualificação 
profissional para outras ocupações e serviços em outras áreas, já que a grande maioria dos entrevistados não apresenta escolaridade capaz de suprir as necessidades de um mercado capitalista industrial, sendo possível observar a existência de um grau de dependência da sociedade com as atividades de exploração dos recursos naturais. (TERCEIRO; SANTOS; CORREIA, 2013).

A mariscagem tem características predominantemente de subsistência, realizada principalmente em grupo, observando-se as relações familiares e de vizinhança, conforme destacado por cerca de $83,33 \%$ dos entrevistados da comunidade Porto do Braga (Raposa), que responderam realizar a atividade em grupo, constituído por parentes ou vizinhos, variando de 2 a 10 pessoas/coleta, com média de 5,8 pessoas/coleta.

O tempo médio para acessar a área de extração é de aproximadamente 1 hora, sendo o principal meio de acesso à croa (área exposta na baixamar) a canoa movimentada com o remo. A coleta sempre é realizada dependendo da dinâmica da maré, (ocorrendo) e ocorre no período entre a enchente e a vazante (baixa mar), intervalos em que as croas ficam expostas, facilitando a catação, que dura em média 4 horas. A periodicidade da extração ocorre de 3 a 4 vezes/ semana, observando a otimização no processo de extração de molusco. Estudos realizados por Moreira (2007), no município de Raposa, demostraram que $46 \%$ dos entrevistados realizavam a atividade 3 a 4 vezes por semana, enquanto Dias, Rocha e Damasceno (2007) assinalaram 2 a 7 dias na semana (média de 4,8 dias/semana) na Ponta do Tubarão, no Rio Grande do Norte.

Dos utensílios utilizados para coleta de moluscos, a pá $(38,08 \%)$ teve destaque no município de Raposa. Uma das situações identificadas quanto à forma de coleta é que não há seleção dos moluscos por tamanho, nos casos em que ocorre o uso da pá, provocando, assim, a redução no desenvolvimento da produção das croas. Segundo Moreira (2007), o tamanho de captura serve como indicador do estágio de desenvolvimento reprodutivo das espécies, pois interessa devido à necessidade de conservação deste recurso pesqueiro. De acordo com Arruda-Soares, Schaeffer-Novelli e Mandelli Jr (1982) a Anomalocardia brasiliana com $20 \mathrm{~mm}$ já pode ser considerada sexualmente madura, sendo considerado o tamanho mínimo sustentável de captura. 
Tatiana de Jesus Ferreira Pereira $\mid$ Antonio Carlos Leal de Castro $\mid$ Helen Roberta Silva Ferreira $\mid$ Leonardo Silva Soares, Marcelo Henrique Lopes Silva $\mid$ James Werllen de Jesus Azevedo $\mid$ Victor Lamarão de França

Os principais moluscos extraídos foram sarnambi de lama (Anomalocardia brasiliana), sururu de pasta (Mytellafalcata), sururu a punho (Mytellaguaniense), tarioba (Iphigeniabrasiliensi), ostras (Crassostrearhizophorae) e unha-de-velho (Tagelusplebeius) ilustrados abaixo.

Figura 2 - Principais moluscos extraídos pela comunidade de catadores da llha do Maranhão

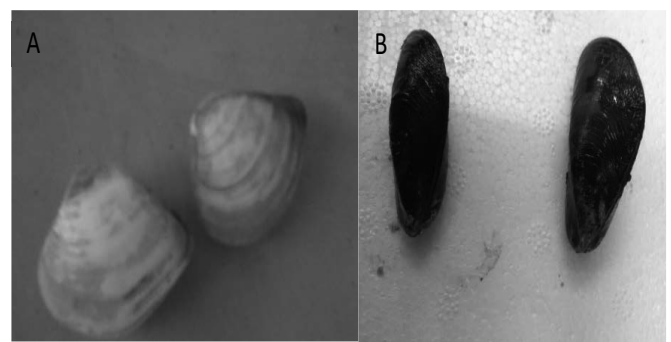

C

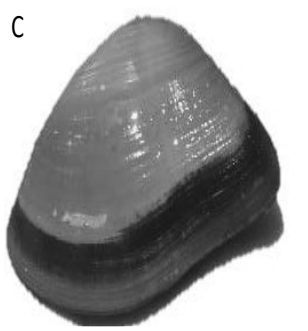

D

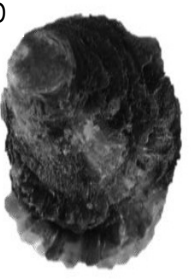

(A): sarnambi (Anomalocardia brasiliana), (B): sururu de pasta (Mytellafalcata), (C): tarioba (Iphigenia brasiliensis) e (D): ostra de mangue (Crassostrearhizophorae).

Fonte: Elaborada pelos autores.

Aspectos referentes às denominações populares dos moluscos, correspondência científica e habitat são apresentados na Tabela 1 .

Tabela 1 - Características gerais dos moluscos coletados de importância comercial

\begin{tabular}{|c|c|c|}
\hline Nome popular & Nome cientifico & Habitat \\
\hline Sarmanbi & Anomalocardia brasiliana & Bancos areno-lodosos \\
\hline Sururu de pasta & Mytella falcata & Substrato lodoso do maguezal \\
\hline Sururu de dedo & Mytella guayanensis & Substrato de manguezal \\
\hline Tarioba & Iphigenia brasiliensis & Bancos areno-lodosos \\
\hline Ostras & Crassostrea rhizophorae & Fixa/aderida em raiz de mangue \\
\hline Unha-de-velho & Tagelus plebeius & Banco areno-lodosos \\
\hline
\end{tabular}

Fonte: Elaborada pelos autores. 
Quando questionados sobre os períodos de maior e menor produção, associaram a produtividade a alguns fatores como: estação sazonal (seca e chuvosa), poluição e variação da maré. No entanto, a coleta ocorre durante todo o ano, mas a produção em alta escala é acentuada na época de estiagem (poucas chuvas), reduzindo sensivelmente no período chuvoso, especialmente para Mytellafalcata, em decorrência da diminuição de salinidade.

Souto e Martins (2009) descrevem A. brasiliana como um animal euritérmico e euriahalino, permitindo uma maior resistência às condições encontradas na época chuvosa e na estiagem, sofrendo, consequentemente, pequena variação estacional.

Registros na literatura evidenciam que durante a maré de lua cheia os mariscos apresentam-se com maior peso corporal. Segundo Nishida (2000), as marés de sizígia, de grande amplitude, produzem uma dinâmica muito acentuada durante a preamar, atingindo bancos areno-lodosos e formando uma espuma que deve conter micro-organismos do plâncton floculados, os quais servirão de alimento para o bivalve e incremento no seu processo de engorda.

Os recursos são capturados em diversos pontos ao longo de todo o manguezal em áreas com nomenclatura localmente conhecidas para os catadores. Neste estudo, as localidades mais citadas foram: Carimã (31,38\%) na Raposa, croa do Mirititiua (27,14\%) em São José de Ribamar e Sarnambizinho $(28,40 \%)$ em Paço do Lumiar.A frequência de captura constitui um dos critérios preponderantes para seleção dos locais de coleta, uma vez que traduz a disponibilidade de recurso e a facilidade de acesso.

A teoria do forrageio ótimo busca identificar a relação efetiva da exploração de pescados considerando a distância e quantidade de produção, observando a vantagem econômica e modo de extração. (NISHIDA; NORDI; ALVES, 2004; PACHECO et al., 2006). Este postulado procura entender o comportamento de forrageio humano em busca de rendimentos que resultem em benefício individual, com maior produção líquida, envolvendo os custos de tempo e energia na atividade.

Nesse sentido, foram destacados alguns locais de coleta pelas comunidades entrevistadas, que consideraram a dinâmica de exploração das croas e a sua capacidade de restauração durante um perí- 
odo de tempo, permitindo o manejo e a conservação dos estoques explorados.

A produção estimada das comunidades pesquisadas variou entre 2 a 4 sacos/coleta, onde cada saco pesa $80 \mathrm{~kg}$, correspondendo à produtividade média de 226,07 kg em São Jose de Ribamar, $221,75 \mathrm{~kg}$ em Raposa e 145,62 kg em Paço do Lumiar.

As marisqueiras realizam o beneficiamento dos mariscos no mesmo dia em que o capturam, em suas próprias casas, auxiliadas por membros da família ou vizinhança. No caso do sarnambi, o processamento segue as seguintes fases: lavagem após coleta com água do estuário, ensacamento, transporte até as residências, cozimento à lenha, retirada da casca com a mão ou, em alguns casos, usam peneira ou monobloco para facilitar a saída da casca. O sururu a punho recebe a lavagem, cozimento e a retirada da casca, enquanto para o sururu de pasta normalmente se faz a sambuca (retirada do umbigo), cozimento e extração da casca. Logo após essa etapa são ensacados e armazenados em geladeira ou freezer para posterior comercialização.

A venda do produto é realizada por atravessadores, consumidores ou representantes da fábrica de beneficiamento, sem nenhum tipo de processamento. O preço de venda do sururu variou de $\mathrm{R} \$$ 15,00 a $\mathrm{R} \$ 20,00$ e o sarnambi de $\mathrm{R} \$ 7,00$ a $\mathrm{R} \$ 10,00$. Identificou-se que a renda decorrente da produção variou segundo as condições de maré e a demanda dos compradores, alcançando valores médios de $\mathrm{R} \$ 200,00 /$ mês (período de baixa produção) e R $\$ 600,00$ /mês (período de maior produção).

Nas comunidades entrevistadas percebeu-se uma forte relação com o uso dos moluscos tanto na economia doméstica, quanto na construção de casas, sendo uma fonte de renda através da venda da carapaça para a fabricação de ração, bem como uma alternativa para o tipo de construção de alvenaria, em substituição à pedra brita e no aterro de áreas residenciais. A reutilização da carapaça apresenta-se como alternativa, pois acaba se tornando resíduo da produção, com valor acrescido à renda familiar.

No que se refere às transformações ocorridas ao longo do tempo de exploração dos moluscos, os entrevistados destacaram a diminuição na captura de espécies e o aumento no esforço de catação. A Tabela 2 descreve os principais tensores ambientais listados, 
EXTRATIVISMO DE MARISCOS NA ILHA DO MARANHÃO (MA): implicações Ecológicas e Socioeconômicas

por ordem de classificação pelas marisqueiras, em todas as comunidades pesquisadas.

Tabela 2 - Principais tensores ambientais identificados pelas comunidades

\begin{tabular}{|c|c|c|}
\hline Ordem & Principais tensores ambientais & Consequência \\
\hline 1 & Esgoto & $\begin{array}{l}\text { Contaminação de compostos orgânicos pra } \\
\text { ambiente aquático. }\end{array}$ \\
\hline 2 & Lixo & $\begin{array}{l}\text { Poluição ou contaminação do ambiente } \\
\text { aquático }\end{array}$ \\
\hline 3 & Redução dos bancos de sururu & Redução da atividade exploratória \\
\hline 4 & Desmatamento & Vegetação de mangue reduzida \\
\hline 5 & Aumento do esforço de extração & $\begin{array}{l}\text { Diminuição da produtividade dos recursos } \\
\text { pesqueiros }\end{array}$ \\
\hline 6 & Catação excessiva & $\begin{array}{l}\text { Morte acentuada de moluscos sobre os } \\
\text { locais de coleta e redução do estoque }\end{array}$ \\
\hline 7 & $\begin{array}{l}\text { Extração predatória de indivíduos } \\
\text { jovens }\end{array}$ & Redução do estoque \\
\hline 8 & Poluição do mar com óleo de barco & Contaminação \\
\hline 9 & $\begin{array}{l}\text { Destino dos resíduos de fossa para } \\
\text { o estuário }\end{array}$ & $\begin{array}{l}\text { Contaminação por microrganismos } \\
\text { entéricos }\end{array}$ \\
\hline 11 & Uso de pá & $\begin{array}{l}\text { Provável redução dos estoques de } \\
\text { moluscos }\end{array}$ \\
\hline 11 & $\begin{array}{l}\text { Queimada nos bancos de sururu } \\
\text { para atrair peixes }\end{array}$ & Poluição e morte do sururu \\
\hline 12 & $\begin{array}{l}\text { Lançamento de resíduos de } \\
\text { alumínio dentro do mangue }\end{array}$ & $\begin{array}{l}\text { Liberação de compostas de metais para } \\
\text { ambiente aquático }\end{array}$ \\
\hline 13 & Fiscalização deficiente & $\begin{array}{l}\text { Ausência de controle ambiental nas } \\
\text { atividades desenvolvidas }\end{array}$ \\
\hline
\end{tabular}

Fonte: Elaborada pelos autores.

$\mathrm{Na}$ avaliação dos moradores, os principais tensores ambientais foram: lançamento de esgoto no manguezal, lixo e desmatamento. Segundo Rodrigues e outros (2001), a zona costeira é afetada pela contaminação, sendo que cerca de $83 \%$ decorrem de atividades terrestres, como derramamento de petróleo, introdução de esgoto doméstico e industrial, ocupação irregular e receptáculo de resíduo sólido.

Outros problemas ambientais ocorridos nas áreas estão relacionados à superexploração dos mariscos, coleta de exemplares com tamanho abaixo do padrão comercial, desmatamento e invasão de pessoas de outras localidades. A maior preocupação é com o desaparecimento de mangues dos mariscos, que segundo entrevistados 
de São Jose de Ribamar ocorre há cinco anos na região, causando desequilíbrio em toda a cadeia de produção.

A substituição das áreas de manguezal tem sido expressiva, em que pese o conhecimento notório que a supressão ou degradação deste ambiente resulta em impactos ambientais e socioeconômicos negativos, uma vez que diminui a produtividade natural, modifica a paisagem e força a saída de populações locais. (TERCEIRO; SANTOS; CORREIA, 2013).

De acordo com Mochel e outros (2013), a Ilha do Maranhão perdeu cerca de 7 mil hectares de manguezal no período de 1972 (25.800 ha) a 1993 (18.900 ha), representando cerca de $27 \%$ de seus manguezais no período de 21 anos.

Não raramente, associam-se as áreas de manguezais impactados às periferias das grandes cidades e à presença de população de menor poder aquisitivo e baixo nível de instrução. Uma ferramenta de relevante importância na detecção, descrição, quantificação e monitoramento de alterações ambientais é o Sistema de Informação Geográfica (SIG), o qual combinado com dados de Sensoriamento Remoto torna-se uma ferramenta de manejo de grande valia para os ecossistemas em geral. (KRUG; LEÃO; AMARAL, 2007).

A produtividade dos ecossistemas estuarinos, aliada ao fato da crescente demanda da exploração de seus recursos naturais e das atividades econômicas desenvolvidas nestas áreas, faz crescer a necessidade de implantarem-se atividades sistemáticas de monitoramento para gerar informações e acompanhar a situação ecológica desses ecossistemas, visando a sua utilização racional. (SANTOS, 2008).

Os dados obtidos na análise multitemporal e espacial das áreas sob influência dos bancos de mariscos (buffer de $3 \mathrm{Km}$ ) revelaram que no ano de 2005 a região dos manguezais da área em estudo equivalia a1.473,37 ha, sendo reduzida para $1.452,45$ ha no ano de 2015, em detrimento ao aumento da expansão urbana (Figura 3). Esta redução confirma que a dinâmica e a distribuição espaço-temporal desse ecossistema vem apresentando grandes alterações em virtude do crescimento da ocupação da zona costeira por áreas urbanas e industriais. 
Figura 3 - Uso e ocupação do solo nas áreas estudadas nos anos de 2005 e 2015

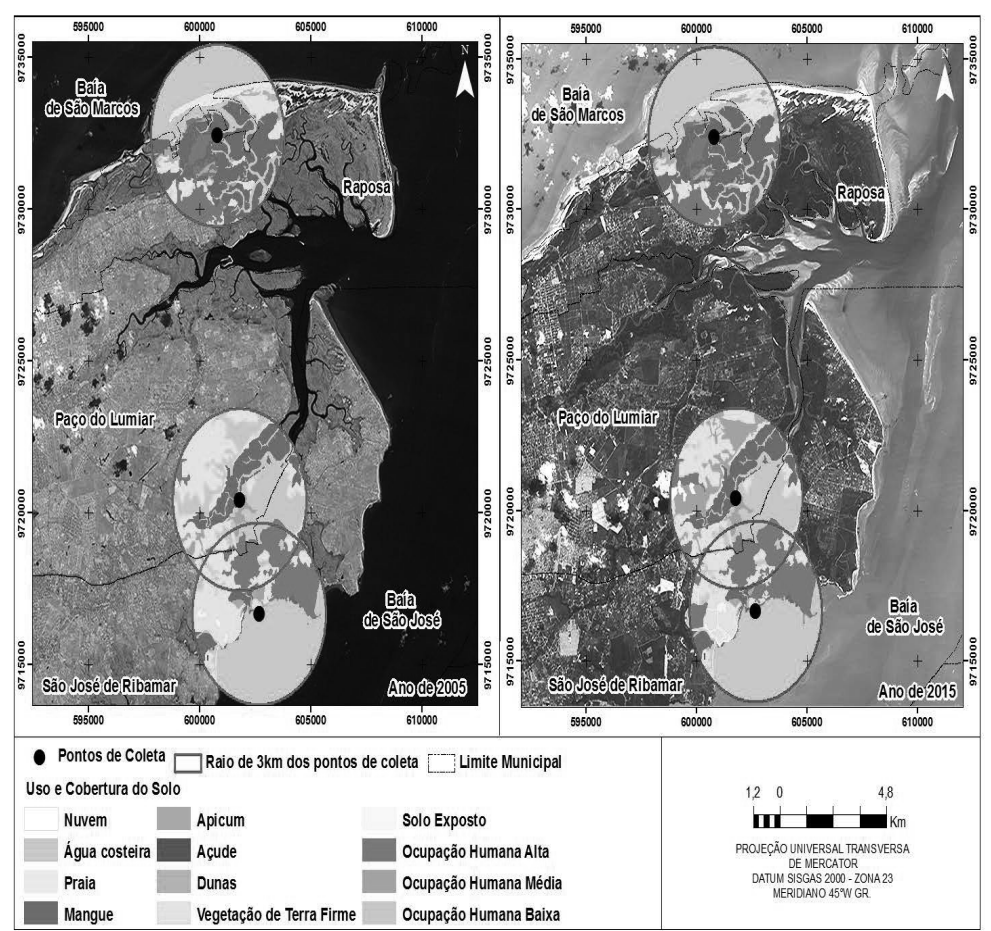

Fonte: Elaborada pelos autores.

Em São Luís, a degradação dos manguezais parece mais acelerada de 1991 a 1993, com perda de áreas de manguezais equivalentes a 2.000 ha contra 5.000 ha no período de vinte anos. (REBELO-MOCHEL et al., 2001). Esse ecossistema vem sofrendo pressão pelo aumento da população na região costeira e consequentes atividades, como aterro para expansão urbana, industrial e portuária, lançamento de esgoto e lixo, além de uma superexploração de seus recursos naturais, como extração de madeira, pesca predatória e desmatamento para atividades de maricultura.

A área urbana tem crescido ao longo do tempo sem incluir a dimensão ambiental no seu planejamento, gerando impactos diretos nos recursos naturais, uma vez que a falta de saneamento básico representa uma das principais causas da poluição e contaminação do ambiente, alterando substancialmente a paisagem. 
Tatiana de Jesus Ferreira Pereira $\mid$ Antonio Carlos Leal de Castro $\mid$ Helen Roberta Silva Ferreira $\mid$ Leonardo Silva Soares, Marcelo Henrique Lopes Silva | James Werllen de Jesus Azevedo | Victor Lamarão de França

No que se refere à análise microbiológica na carne de moluscos e da água de estuário, o Programa Nacional de Controle Higiênico Sanitário de Moluscos Bivalves (PNCMB) determinou parâmetros mínimos na garantia da qualidade dos moluscos bivalves destinados ao consumo humano no Brasil, a partir da densidade média dos micro-organismos contaminantes. (BRASIL, 2011). O critério utilizado considera os seguintes valores:

- $<300 \mathrm{NMP} / 100 \mathrm{~g}^{-1}$ liberada para consumo;

- $\geq 300$ e $\leq 6.000 \mathrm{NMP} / 100 \mathrm{~g}^{-1}$ liberada sob condição (submeter ao processo de depuração);

- $6.000 \mathrm{NMP} / 100 \mathrm{~g}^{-1}$ proibido para consumo.

Os resultados encontrados para este estudo mostram que a contagem de coliformes totais e a $45^{\circ} \mathrm{C}$ na carne dos moluscos foi enquadrada na classe liberada para consumo no município de Paço do Lumiar (93 NMP/100g) e São José de Ribamar (240 NMP/100g e $75 \mathrm{NMP} / 100 \mathrm{~g}$ para Coliformes a $45^{\circ}$ ). Esses valores recomendam muita cautela e um monitoramento constante, para evitar que o aumento da concentração de patógenos comprometa a qualidade dos moluscos e a saúde pública.

Os valores encontrados na carne dos moluscos no município de Raposa foram superiores aos observados nos outros municípios estudados (1.100 NMP/100g para Coliformes Fecais e a $\left.45^{\circ} \mathrm{C}\right)$, enquadrando-os na classe liberada sob condição, devendo ser submetido ao processo de depuração. Por outro lado, constatou-se ausência de Escherichia coli em todas as amostras analisadas (Tabela 3).

Tabela 3 - Resultado das análises microbiológicas do sururu, sarnambi e da áqua nos pontos amostrados

\begin{tabular}{|c|c|c|c|c|c|c|}
\hline \multirow{2}{*}{$\begin{array}{l}\text { Ponto de } \\
\text { coleta }\end{array}$} & \multirow{2}{*}{ Amostra } & \multicolumn{2}{|c|}{$\begin{array}{l}\text { Coliformes totais } \\
\text { NMP } 100 \mathrm{~g}^{-1}\end{array}$} & \multirow{2}{*}{$\begin{array}{l}\text { Coliformes } \\
\text { a } 45^{\circ} \\
\text { NMP } 100 \mathrm{~g}^{-1} \\
\text { Carne do } \\
\text { molusco }\end{array}$} & \multicolumn{2}{|c|}{$\begin{array}{l}\text { Escherichia coli NMP } \\
100 \mathrm{~g}^{-1}\end{array}$} \\
\hline & & $\begin{array}{l}\text { Carne do } \\
\text { molusco }\end{array}$ & $\begin{array}{l}\text { Água do } \\
\text { estuário }\end{array}$ & & $\begin{array}{l}\text { Carne do } \\
\text { molusco }\end{array}$ & $\begin{array}{l}\text { Água do } \\
\text { estuário }\end{array}$ \\
\hline $\begin{array}{l}\text { Paço do } \\
\text { Lumiar } \\
\text { - Porto } \\
\text { de Pau } \\
\text { Deitado }\end{array}$ & $\begin{array}{l}\text { Sururu de } \\
\text { pasta }\end{array}$ & 93 & 2400 & 93 & Ausência & 1732 \\
\hline
\end{tabular}


EXTRATIVISMO DE MARISCOS NA ILHA DO MARANHÃO (MA): implicações Ecológicas e Socioeconômicas

\begin{tabular}{l|l|l|l|l|l|l}
\hline $\begin{array}{l}\text { São } \\
\text { José de } \\
\begin{array}{l}\text { Ribamar - } \\
\text { Mirititiua }\end{array}\end{array}$ & $\begin{array}{l}\text { Sarnambi } \\
\text { de areia }\end{array}$ & 240 & 2400 & 75 & Ausência & 2400 \\
\hline $\begin{array}{l}\text { Raposa - } \\
\text { Porto do } \\
\text { Braga }\end{array}$ & $\begin{array}{l}\text { Sururu a } \\
\text { punho }\end{array}$ & 1100 & 2400 & 1100 & Ausência & 2400 \\
\hline
\end{tabular}

Fonte: Elaborada pelos autores.

A alta concentração de coliformes, assim como a presença de Escherichiacoli nas amostras de água, indicam contaminação por material fecal, provavelmente devido à falta de saneamento nas comunidades circunvizinhas das áreas dos municípios investigados.

Vieira (2004) assinala que a ingestão de bactérias como a E. coli pode causar pelo menos seis tipos de infecções intestinais que podem levar a óbito desde crianças com idade inferior a 6 meses, a adultos. Dentre os sintomas destacam-se: diarreia aguda, diarreia aquosa, diarreia severa, diarreia profusa, dores abdominais, vômitos, febre, náuseas, desidratação, sangue nas fezes, dor de cabeça e dores musculares. Essas infecções podem durar de 6 horas até 14 dias. Além disso, altos valores de E. coli podem ser indicadores de possíveis contaminações de outros micro-organismos patogênicos humanos de veiculação hídrica.

\section{CONCLUSÃO}

Os principais moluscos extraídos foram sarnambi de lama (Anomalocardia brasiliana), sururu de pasta (Mytellafalcata), sururu a punho (Mytellaguaniense), tarioba (Iphigeniabrasiliensi), ostras (Crassostrearhizophorae) e unha-de-velho (Tagelusplebeius).

A mariscagem tem papel fundamental no sustento das famílias pesquisadas, representando uma fonte de renda adicional, que variou de 42,86\% (Raposa) a 66,67\% (São José de Ribamar), com tempo médio de 16,45 anos.

Os catadores possuem em sua maioria ensino fundamental incompleto, que corresponde entre $44,44 \%$ a $50,00 \%$, seguido por analfabetismo com $11,11 \%$ a $28,57 \%$.

$\mathrm{Na}$ avaliação dos moradores, os principais tensores ambientais foram: lançamento de esgoto no manguezal, lixo e desmatamento. 
Tatiana de Jesus Ferreira Pereira $\mid$ Antonio Carlos Leal de Castro $\mid$ Helen Roberta Silva Ferreira $\mid$ Leonardo Silva Soares, Marcelo Henrique Lopes Silva | James Werllen de Jesus Azevedo | Victor Lamarão de França

A análise multitemporal e espacial das áreas sob influência dos bancos de mariscos (buffer de $3 \mathrm{Km}$ ) revelou uma redução nos habitats de manguezais, comparando o ano de 2005 (1.473,37 ha) com o ano 2015 (1.452,45 ha), o que foi atribuído ao aumento da expansão urbana.

A carne dos moluscos analisados foi enquadrada na classe liberada para consumo com referência a Coliformes Totais e a $45^{\circ} \mathrm{C}$, para os municípios de Paço do Lumiar (93 NMP100/g) e São José de Ribamar (240 NMP 100/g para Coliformes Fecais e75 NMP 100/g para Coliformes a $45^{\circ}$ ), enquanto no município de Raposa foi enquadrada na categoria liberada sob condição $(1.100 \mathrm{NMP} / 100 \mathrm{~g}$ para Coliformes Fecais e a $45^{\circ} \mathrm{C}$ ), devendo ser submetido ao processo de depuração.

\section{REFERÊNCIAS}

ALEXIADES, M. N. Selected guildelines for ethnobotanical research: a field manual. New York: NYBG, 1996.

AMERICAN PUBLIC HEALTH ASSOCIATION. Standard Methods for the Examination of Water and Wastewater. 20. ed. [S. 1.]: APHA, AWWA, WEF, 2005.

ARRUDA-SOARES, H.; SCHAEFFER-NOVELLI, Y.; MANDELLI JR., J. "Berbigão" Anomalocardia brasiliana (Gmelin, 1791), bivalve comestível da região da Ilha do Cardoso, Estado de São Paulo, Brasil: aspectos biológicos de interesse para a pesca comercial. Boletim do Instituto de Pesca, São Paulo, v. 9, p. 21-38, 1982.

BRASIL. Programa Nacional de Controle Higiênico Sanitário de Moluscos Bivalves (PNCMB). Instrução Normativa Interministerial. Portaria $\mathrm{n}^{\circ} 122$, de 4 de maio de 2011. Diário Oficial da União, Brasília, DF, p. 28. 2011.

CARVALHO, G. P. et al. Preliminaryassessmentof heavy metal levels in Mytellafalcata (Bivalvia, Mytilidae) from Bacana River Estuary, São Luís, Stateof Maranhão, NortheasternBrazil. Revista Brasileira de Biologia, São Carlos, v. 60, n. 1, p. 11-16, fev. 2000.

CASTILHO-WESTPHAL, G. G. et al. Comunidades ribeirinhas extrativistas e a exploração de bancos de ostras do mangue Crassostreasp., na baía de Guaratuba - Paraná, litoral Sul do Brasil. Bioscience Journal, Urbelandia, v. 30, n. 5, p. 912-923, 2014. 
CASTRO, A. C. L. et al. Manual de Cultivo de Ostra. São Luís: Departamento de Oceanografia e Limnologia. Fundação de Amparo à Pesquisa de Estado do Maranhão - FAPEMA, 2014.

CORDELL, J. The lunar-tidefishingcycle in Northeastern Brazil. Ethnology, [S. 1.], v. 13, n. 4, 2001.

DALTRO, A.C.S. Aspectos socioeconômicos e qualidade dos moluscos bivalves através do monitoramento microbiológico e genético. 2013. Dissertação (Mestrado em Ciência Animal) Universidade Federal do Recôncavo da Bahia, Salvador, 2013.

DIAS, T. L. P.; ROSA, R. de S.; DAMASCENO, L. C. P. Aspectos socioeconômicos, percepção ambiental e perspectivas das mulheres marisqueiras da Reserva de Desenvolvimento Sustentável Ponta do Tubarão (Rio Grande do Norte, Brasil). Gaia Scientia, João Pessoa, v. 1, n. 1, p. 25-35, 2007.

DIEGUES, A. C. S. Pescadores, camponeses e trabalhadores do mar. São Paulo: Ed. Ática., 1983. (Série Ensaios, n. 94).

FEITOSA, A. C.; TROVÃO, J. R. Atlas escolar do Maranhão: espaço geo-histórico e cultural. João Pessoa: Grafset, 2006.

FUNO, I. C. da S. A. et al. Saberes e fazeres de marisqueiras do município de Raposa-MA. In: ENCONTRO NACIONAL DOS NÚCLEOS DE PESQUISA APLICADA EM PESCA E AQUICULTURA, 4., Foz do Iguaçu, 2012. Anais... Foz o Iguaçu, 2012.

KRUG, L. A.; LEÃO, C.; AMARAL, S. Dinâmica espaço-temporal de manguezais no Complexo Estuarino de Paranaguá e relação entre decréscimo de áreas de manguezal e dados sócio-econômicos da região urbana do município de Paranaguá-Paraná. In: SIMPÓSIO BRASILEIRO DE SENSORIAMENTO REMOTO, 13., Florianópolis, 2007. Anais... Florianópolis: INPE, 2007. p. 2753-2760.

MARQUES, J. G. W. Pescando pescadores: etnoecologia abrangente no baixo São Francisco alagoano. São Paulo: NUPAUB/USP, 1995.

MOCHEL, F. R. et al. Degradação dos manguezais na Ilha de São Luís (MA) processos naturais e antrópicos. In: PROSTE, M. T.; MENDES, A. C. (Orgs.) Ecossistemas costeiros: impactos e gestão ambiental. 2. ed. rev. atual. Belém: Museu Paraense Emilio Goeldi, 2013. p.113-130. 
Tatiana de Jesus Ferreira Pereira $\mid$ Antonio Carlos Leal de Castro $\mid$ Helen Roberta Silva Ferreira $\mid$ Leonardo Silva Soares, Marcelo Henrique Lopes Silva | James Werllen de Jesus Azevedo | Victor Lamarão de França

MONTELES, J. S. et al. Percepção socio-ambiental das marisqueiras no município de Raposa, Maranhão, Brasil. Revista Brasileira de Engenharia de Pesca, [S. 1.], v. 4, n. 2, p. 34-45, 2009.

MOREIRA, I. C. de N. Impactos do extrativismo de Anomalocardia brasiliana (Gmelin, 1791) nos estuários dos rios Paciência e Cururuca, São Luís, Maranhão: uma visão etnoconservacionista. 2007. 60 f. Dissertação (Mestrado em Biodiversidade e Conservação) Universidade Federal do Maranhão, São Luís, 2007.

NISHIDA, A. K. Catadores de moluscos do litoral Paraibano. Estratégias de subsistência e formas de percepção da natureza. 2000. 143 f. Tese (Doutorado) - Pós-Graduação em Ecologia e Recursos Naturais, Centro de Ciências Biológicas e da Saúde, Universidade Federal de São Carlos, São Carlos, 2000.

; NORDI, N.; ALVES, R. R. da N. Abordagem etnoecológica da coleta de moluscos no litoral paraibano. Tropical Oceanography, Recife, v. 32, n. 1, p. 53-68, 2004.

molus $\quad$ Aspectos socioeconômicos dos catadores de e Ciências da Terra, São Cristovão, SE, v. 8, n. 1, jan./jun. 2008.

PACHECO, R. S. et al. Pesca e Uso dos Recursos Aquáticos por uma População Pesqueira Residente na Baía de Camamu - BA. In: ENCONTRO DA ASSOCIAÇÃO NACIONAL DE PÓSGRADUAÇÃO E PESQUISA EM AMBIENTE E SOCIEDADE, 3., Brasília, DF, 2006. Anais... Brasília, DF: ANPPAS, 2006.

POLI, C. R. Cultivo de Crassostrea gigas (Thunberg, 1795) no sul do Brasil. Florianópolis: UFSC, 1996. Trabalho de Defesa de Exame para Professor Titular.

REBELO-MOCHEL, F. R. et al. Degradação dos Manguezais na Ilha de São Luís (MA): Processos Naturais e Impactos Antrópicos. In: PROST, M. T.; MENDES, A. C. (Orgs.). Ecossistemas Costeiros: impactos e gestão ambiental. Belém: Museu Paraense Emílio Goeldi, 2001. p.113-131.

ROCHA, M. da S. P. Mulheres, manguezais e a pesca no estuário do rio Mamanguape, Paraíba. 2010. 122 f. Dissertação (Mestrado) Programa Regional de Pós-Graduação em Desenvolvimento e Meio Ambiente, Universidade Federal da Paraíba, João Pessoa, 2010. 
RODRIGUES, C. A. L. et al. Patterns of mollusc distribution in mangroves from the São Marcos Bay, coast of Maranhão State, Brazil. Acta Amazonica, Manaus, v. 46, n. 4, p. 391-400, out./dez. 2016.

SANTOS, D. A. O zooplâncton como indicador da qualidade ambiental do Parque dos Manguezais de Pernambuco. 2008. 106 f. Dissertação (Mestrado em Biologia Animal) - Universidade Federal de Pernambuco, Recife, 2008.

SCHAEFFER-NOVELLI, Y. Avaliação e ações prioritárias para a conservação da biodiversidade da zona costeira e marinha. São Paulo: Universidade de São Paulo, Instituto Oceanográfico, 1999. Relatório Técnico.

Perfil dos ecossistemas litorâneos brasileiros, com especial ênfase sobre o ecossistema manguezal. São Paulo: Instituto Oceanográfico, 1989. (Publicação especial do Instituto Oceonográfico, n. 7).

SOUTO, F. J. B. A ciência que veio da lama: uma abordagem etnoecológica das relações ser humano/manguezal na comunidade pesqueira de Acupe, Santo Amaro-BA. 2004. 319 f. Tese (Doutorado) - Universidade Federal de São Carlos, São Carlos, 2004.

; MARTINS, V. S. Conhecimentos etnoecológicos na mariscagem de moluscos bivalves no Manguezal do Distrito de Acupe, Santo Amaro - BA. Biotemas, Florianópolis, v. 22, n. 4, p. 207-218, 2009.

TERCEIRO, A. B.; SANTOS, J. J. S.; CORREIA, M. M. F. Caracterização da sociedade, economia e meio ambiente costeiro atuante à exploração dos manguezais no estado do Maranhão. Revista de Administração e Negócios da Amazônia, Porto Velho, v. 5, n. 3, p. 94-111, 2013.

VERGARA-FILHO, W. L.; VILLAS BOAS, M. S. Introdução ao saber dos povos da lama. In: ENCONTRO NACIONAL DE EDUCAÇÃO AMBIENTAL EM ÁREAS DE MANGUEZAIS, 4., Nova Almeida, 1996. Resumos... Nova Almeida: Universidade Federal do Espírito Santo, 1996. p 22-29.

VIEIRA, R.H.S. F. Microbiologia, higiene e qualidade do pescado: teoria e prática. São Paulo: Ed. Varela, 2004. 
